\title{
INDICADORES DE DESEMPENHO ZOOTÉCNICO OBSERVADOS NAS UNIDADES DE PRODUÇÃO FAMILIAR ASSOCIADAS À COOPERATIVA DOS PRODUTORES DE LEITE DE SANTA MARIA (COOPROL), RS ${ }^{1}$
}

\author{
ZOOTECHNICAL PERFORMANCE INDEXES OBSERVED IN FAMILY \\ PRODUCTION UNITS ASSOCIATED TO THE "COOPERATIVA DOS PRODUTORES \\ DE LEITE DE SANTA MARIA”(COOPROL), RS, BRAZIL
}

\author{
Jorge Nunes Portela ${ }^{2}$ Julio Viegas $^{3}$ Pedro Selvino Neumann $^{4}$ \\ Luciany Dias Laurentino ${ }^{5}$ Guido Castagnino ${ }^{5}$
}

RESUMO

O presente trabalho teve o objetivo de identificar o desempenho zootécnico das unidades de produção familiar (UPFs) associadas à Cooperativa dos Produtores de Leite de Santa Maria (COOPROL), RS, que desenvolvem a atividade leiteira combinada ou não com outras atividades vegetal elou animal. Foram coletadas as informações de um grupo de 53 UPFs, sendo identificados nove sistemas de produção. Nestes sistemas, a idade média ao primeiro parto (IPP) variou de 2,5 a 3 anos, o intervalo entre partos (IEP) de 456 a 520 dias, o período seco (PS) de 91 a 260 dias, a taxa de natalidade de 70 a 80\%, a duração média das lactações (DML) de 365 a 387 dias e a produtividade de leite de 2,52 a 13,5 \&vacaldia. Estes valores indicam a necessidade de ações visando readequar o manejo reprodutivo e o sistema alimentar dos rebanhos de cada sistema de produção identificado.

Palavras-chave: unidade de produção familiar, índices zootécnicos e desempenho técnico.

\section{SUMMARY}

The present work studied the zootechnical performance in family production units (UPFs), associated to a co-operative society (COOPROL) in Santa Maria, RS, Brazil.
Some of the studied farms had other animal or agricultural activities associated to the milk production unit. The data were obtained in 53 UPFs, and nine different systems of production were identified. The age at the first calving ranged from 2.5 to 3 years, the calving interval from 456 to 520 days, dry period from 91 to 260 days, birth rate 70 to $80 \%$, lactation length from 365 to 387 days and milk production from 2.52 to 13.5 lcow/day. The numbers above show the need for actions to re-adequate the breeding and alimentary systems used in these home farms.

Key words: family production unit, zootechnical indexes, technical performance.

\section{INTRODUÇÃO}

O trabalho faz parte de uma proposta de desenvolvimento, através da integração multidisciplinar de alguns Departamentos do Centro de Ciências Rurais da Universidade Federal de Santa Maria (UFSM), de um programa de assistência técnica planejada junto aos produtores da Cooperativa dos Produtores de Leite (COOPROL), visando ampliar as suas possibilidades de reprodução sócio-econômica.

\footnotetext{
${ }^{1}$ Parte do trabalho de dissertação apresentado à Universidade Federal de Santa Maria (UFSM), Santa Maria pelo primeiro autor para obtenção do título de Mestre.

${ }^{2}$ Zootecnista, Mestre em Produção Animal. E-mail: jorgenp@eafpjk.com.br

${ }^{3}$ Doutor em Zootecnia, professor do Departamento de Zootecnia, Centro de Ciências Rurais (CCR), UFSM, 97105-900, Santa Maria, RS. E-mail:: jviegas@ccr.ufsm.br

${ }^{4}$ Doutorando em Desenvolvimento Rural, professor do Departamento de Ensino Agrícola e Extensão Rural, UFSM.

${ }^{5}$ Acadêmicos do Curso de Zootecnia, CCR, UFSM.
} 
A atividade leiteira, embora tenha permitido, no decorrer da última década, a sobrevivência e permanência de muitas famílias no meio rural, tem vivenciado momentos de estagnação e de descapitalização acentuada de um significativo percentual de UPFs. Um agravante desta situação é a não operacionalidade, até 1998, dos programas do Estado e a incapacidade de grande parte das instituições em promoverem o desenvolvimento rural, a partir de alternativas reais para que as unidades possam desenvolver-se. Essa incapacidade, provavelmente, seja resultado da dificuldade metodológica dessas instituições em abandonarem o modelo de transferência de pacotes tecnológicos padronizados, cujo resultado acaba sendo o aumento da desigualdade entre produtores que podem ter, ou não, condições de adotar os mesmos.

A situação da produção de leite no RS, comparada com países vizinhos, como Uruguai e a Argentina, não deixa de ser preocupante. Os dados relativos à produção de leite desses países, segundo ESCOSTEGUY et al. (1993), mostram uma estrutura de produção de leite formada pela produção média por estabelecimento de 600 e $660 \mathrm{~kg}$ de leite/dia; produtividade animal de 8,6 e $11,54 \mathrm{~kg}$ de leite/vaca/dia; rebanho médio por estabelecimento de 70 e 57 vacas em lactação; área média destinada à produção de leite de 100 e 244ha para Uruguai e Argentina, respectivamente.

No RS, os dados médios relatam uma situação do rebanho leiteiro composto de 7 vacas com uma área destinada à produção de leite de 11 ha e a produção total diária de $24,5 \mathrm{~kg}$. A atividade está integrada com outras culturas e criações, sendo a explicação da sobrevivência de algumas UPFs, produzindo e reproduzindo social e economicamente no tempo o que contradiz as políticas de expansão das grandes empresas que hoje dominam o comércio do leite no RS. Fazem parte desta realidade um percentual bastante significativo destas propriedades que se encontram em um processo histórico de empobrecimento gradativo.

No entanto, os dados disponíveis são insuficientes para explicar a atividade leiteira no RS, pois o perfil "médio" de produção não considera a heterogeneidade de situações em que se encontram as propriedades que produzem leite (nas regiões produtoras), principalmente, quando integram e combinam outras produções. Essa situação particular de integração do leite com outras atividades, constitui-se em uma alternativa mais endógena e menos dependente de variáveis externas e escassas às UPFs, aparecendo também como solução dos problemas mais imediatos das propriedades. A presença deste tipo de agricultura (familiar) na
Região Sul (RS e SC), segundo FAO/INCRA (1996), representa 86\% dos estabelecimentos rurais, $39 \%$ da área total ocupada, 52\% do Valor Bruto Produzido (VBP), $19 \%$ do crédito rural e $77 \%$ do pessoal ocupado, portanto é o modelo que mais emprega mão-de-obra por unidade de área agricultável e que apresenta a maior produtividade da terra.

Nesta perspectiva, o desenvolvimento de alternativas apropriadas às diferentes necessidades e condições das UPFs, que possuem na atividade de produção de leite uma das fontes de renda, só será possível a partir do estudo aprofundado das condições reais de produção destas unidades. Requer assim um instrumental metodológico adequado ao estudo da propriedade como um todo organizado. A análise em termos de sistemas de produção permite compreender as combinações e interações dos meios de produção, pela lógica peculiar de funcionamento dos sistemas, ou seja, seu grau de coerência/contradição. Para LIMA et al. (1995), um sistema não é a realidade, mas uma imagem adotada da realidade, considerada aceitável pelo agricultor no momento que é estabelecida. Isto significa que a UPF embora não sendo realmente um sistema pode ser representada por um modelo sistêmico. Considera-se ainda que os estudos sobre sistemas de produção permitem compreender por que as explorações se desenvolvem em ritmos diferentes. Além do mais, permite elaborar a tipologia de produtores, para um melhor desempenho e compreensão da realidade rural por parte dos agentes envolvidos no processo de desenvolvimento.

O presente trabalho teve o objetivo de caracterizar os sistemas de produção de leite praticados pelos produtores associados à COOPROL, buscando subsidiar a determinação de ações diferenciadas para as categorias de produtores, comparar as unidades e correlacionar os resultados obtidos entre os sistemas produtivos encontrados.

\section{MATERIAL E MÉTODOS}

O trabalho foi desenvolvido na região da Depressão Central do RS, no período de janeiro a setembro de 1998, tendo como público alvo as UPFs associadas à COOPROL. As informações foram coletadas em um grupo de 53 propriedades, obtidas através de um instrumento denominado de "enquete" desenvolvido pelo grupo de pesquisa do Departamento de Ensino Agrícola e Extensão Rural, da UFSM. O diagnóstico das UPFs foi caracterizado por três momentos distintos e integrados: o estudo das condições estruturais das mesmas; o estudo do funcionamento das propriedades; o estudo da 
trajetória destas e dos objetivos do agricultor. A análise dos sistemas de produção se caracteriza por ser uma etapa posterior ao levantamento de dados, e tem início na sistematização dos mesmos, reunindo e organizando as informações coletadas.

Os critérios de agrupamento escolhidos estão associados àqueles fatores que diferenciam o processo de desenvolvimento das unidades: combinação das produções com fim comercial (variável predominante), características do ecossistema cultivado (condições de relevo) e disponibilidade dos meios de produção, particularmente, do tipo de força de tração (TA tração animal ou TM - tração mecanizada), da superfície de área útil (SAU) e da mão-de-obra, representada em unidades de trabalho humano (UTH $=$ Equivalente à força de trabalho de um trabalhador adulto (17 aos 59 anos) em 287 jornadas/ano). Buscou-se apresentar uma imagem da realidade de cada sistema de produção, através de um procedimento que adota como referência a aglutinação das características em um modelo típico de UPF de cada sistema.

\section{RESULTADOS E DISCUSSÃO}

Sistema de produção A - este sistema é composto por unidades que combinam a atividade de produção de leite com a cultura do arroz, dispondo em média: 2 UTH; 30ha de SAU, distribuídas em 6ha para a cultura do arroz (Oryza sativa), 4,5ha de milho (Zea mays), 1,5ha de mandioca (Manihot esculenta), 0,5ha de cana-de-açúcar (Saccharum officicinarum) para forragem), 2ha de pastagens anuais de inverno aveia/azevém (Avena strigosa e Lolium multiflorum), tha de pastagem anual de verão, usualmente milheto (Pennisetum americanum) e 16,5ha de campo nativo; apresenta restrições na disponibilidade de SAU destinada à cultura do arroz, devido às condições ecológicas de encosta; os equipamentos disponíveis são de uso manual e TA.

A atividade leiteira se caracteriza pela baixa escala de produção de, aproximadamente, 15 litros de leite comercializados/dia. Em relação ao rebanho, este é constituído por 10 vacas, 7 terneiros, 4 novilhas de um ano e meio, 3 novilhas com mais de dois anos e 2 bois para tração prevalecendo animais mestiços Holandês/Zebu. A inseminação artificial como prática não é utilizada no manejo do rebanho leiteiro. A carga animal utilizada no sistema é incoerente com a oferta alimentar disponível, o que provoca uma acentuada carência, principalmente, no período de outono e terço final da primavera.

A variável reprodutiva IPP de 3 anos evidencia uma limitação de manejo, uma vez que, se torna um fator de restrição ao aumento na proporção de vacas em lactação. O IEP de 520 dias, demasiadamente longo, é conhecido como o intervalo de tempo no qual a vaca pariu, desenvolveu a lactação, foi coberta, entrou em gestação, foi seca e ocorreu o novo parto, sendo uma conseqüência direta das limitações do sistema no plano de forrageamento, para atender as demandas do rebanho no decorrer do ano agrícola. Segundo levantamento realizado por HILLESHEIM \& STUKER (1995), sobre IEP em propriedades leiteiras na região Leste de $\mathrm{SC}$, foi constatado que a média das unidades gira em torno dos 390 dias, próximo ao ideal que seria de 365 dias, meta difícil de ser atingida mesmo em bacias leiteiras especializadas, como a Castrolanda no PR, cujo intervalo está próximo de 416 dias. O PS médio de 155 dias está diretamente correlacionado à baixa persistência de lactação, mais acentuada nos animais mestiços. A taxa de natalidade $(70 \%)$ aparece como uma resposta inversa ao IEP, ou seja, quanto mais longo for este, menor será o percentual de natalidade obtido no sistema.

Valores de DML, quando muito longos (365 dias), demonstram falhas no aparecimento ou na visualização do cio pós-parto, provocando situações na qual o leite é retirado de uma mesma vaca por dois anos ininterruptamente. A produtividade de 4,0 $\ell /$ vaca/dia torna insustentável a permanência do agricultor no meio, produzindo ao longo do tempo, principalmente, quando a cultura do arroz também apresenta baixa escala e produtividade.

Sistema de produção B - este sistema é constituído por unidades que desenvolvem a atividade de produção de leite combinada com a cultura do arroz, dispondo em média: 3 UTH, com uma demanda bastante variável no decorrer do ano agrícola; 54ha de SAU, distribuídas em 22ha para a cultura do arroz, 14,5ha de milho, 0,5ha de mandioca, tha de cana-de-açúcar, 3,5ha de pastagens anuais de inverno (aveia/azevém) e 16ha de campo nativo; localiza-se em área com maior disponibilidade de várzea, para a cultura do arroz, quando comparado ao sistema $\mathrm{A}$; possui tração mecanizada composta por um trator com potência média de 70HP, mais implementos de cultivo convencional e de uso rotineiro.

A atividade leiteira é caracterizada por uma escala de produção comercializada diariamente com média de 30 $/$ dia. No que se refere à composição do rebanho, este é formado em média por 14 vacas, 9 terneiros, 5 novilhas de um ano e meio, 4 novilhas com mais de dois anos e 1 touro. $\mathrm{O}$ padrão racial predominante no rebanho leiteiro é o 
mestiço (Holandês/Zebu) procedente de monta natural. As variáveis reprodutivas IPP (3 anos) e IEP (511 dias) limitam o aumento na proporção de vacas em lactação, sendo consequiência da instabilidade do sistema no plano de forrageamento do rebanho. A variação no PS é similar ao sistema $\mathrm{A}$, entretanto, quanto mais acentuada for a predominância de zebuínos no rebanho, maior será este período. A natalidade média de $70 \%$ obtida se situa abaixo dos $82 \%$ alcançados por algumas unidades, podendo ser esta uma meta a ser atingida pelo sistema. Segundo FARIAS \& CORSI (1986), um índice entre 75 e $85 \%$ de nascimentos mantém uma relação com um IEP de 16 a 14 meses, respectivamente, podendo representar uma diminuição no volume dos recursos econômicos, destinados à manutenção da categoria de animais improdutivos.

O resultado da DML de 365 dias reproduz uma situação em que os índices reprodutivos causam efeitos dramáticos na capacidade produtiva do sistema. Para FARIAS \& SILVA (1996), a ampliação na DML de 305 dias para 365, somada aos índices VL (83\%), persistência de produção de leite $(80 \%)$ e IEP (14 meses), influenciam a capacidade de produção de leite, reduzindo a produção por vaca em $29 \%$. A produtividade de

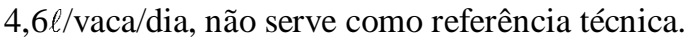

Sistema de produção $\mathrm{C}$ - este sistema é formado por unidades que desenvolvem a atividade de produção de leite combinada com produtos hortigranjeiros, dispõe em média: 2,5 UTH; 20ha de SAU, distribuída em 1ha para a cultura da mandioca, tha de batata-doce (Ipomoea batatas), tha de melancia (Citrulus lonatus), 0,35ha de moranga (Curcubita máxima), 2ha de milho, 1ha de cana-deaçúcar (fim forrageiro), 1ha de pastagens anuais de inverno (aveia/azevém), 1ha de pastagem anual de verão (milheto) e 12,65ha de campo nativo; os equipamentos disponíveis são de uso manual e TA, semelhantes ao sistema A.

A atividade leiteira se distingue por apresentar uma escala de produção superior aos sistemas A e B, aproximadamente $80 \ell$ de leite comercializados/dia. Com relação ao número de animais possuem 15 vacas, 10 terneiros, 5 novilhas de um ano e meio, 4 novilhas com mais de dois anos, 1 touro, 2 bois de serviço e 1 eqüino. Prevalecem no rebanho animais mais especializados na produção de leite (características raciais do Holandês). O uso da técnica de inseminação artificial acontece esporadicamente, somando-se à monta natural.

As variáveis reprodutivas IPP e IEP assemelham-se aos sistemas A e B e evidenciam a necessidade de um planejamento forrageiro integrado que não subestime as variações do clima.
A variação no PS devido ao predomínio de animais com características da raça Holandesa distingue-se dos sistemas anteriores pelo menor intervalo. A taxa de natalidade observada é de $70 \%$, podendo ser o valor de $80 \%$ assumido como objetivo a ser alcançado, uma vez que este desempenho já foi atingido por algumas unidades.

A DML se assemelha aos sistemas anteriores, portanto, falhas reprodutivas propiciam uma lactação mais prolongada. Para LUCCI (1997), as vacas leiteiras tendem a produzir até o quarto ou quinto mês da lactação, mais da metade do volume de leite de uma lactação completa. Portanto, mesmo o produtor trabalhando com rebanhos persistentes, dificilmente manteria um bom desempenho do rebanho, próximo a 365 dias. A produtividade por vaca permanece em $8,8 \ell$ de leite/dia como resultado de um ano de exploração na unidade.

Sistema de produção D - este sistema é composto por unidades que desenvolvem a atividade leiteira combinada com hortigranjeiros, dispõe em média: 3,5 UTH; 50ha de SAU, distribuída em 1,5ha de mandioca, 1ha batata-doce, 10ha de milho, 1ha de sorgo forrageiro (Sorghum vulgare), 0,5ha de canade-açúcar (fim forrageiro), 10ha de pastagens anuais de inverno (aveia/azevém), 1ha de pastagem anual de verão (milheto), 1ha de capim-elefante (Pennisetum purpureum) e 34ha de campo nativo; possui além dos equipamentos de uso manual, os de TA e TM.

A atividade leiteira no sistema $D$ se distingue por uma escala de produção próxima de $110 \ell$ de leite/comercializados/dia. As unidades possuem em média 20 vacas, 14 terneiros, 7 novilhas de um ano e meio, 6 novilhas com mais de dois anos, 1 touro e 1 eqüino, prevalecendo animais com características raciais do Holandês. Utilizam, de forma mais intensiva quando comparados com o sistema C, a técnica de inseminação artificial, complementada com a monta natural. As variáveis reprodutivas IPP, IEP, PS e natalidade apresentam valores de 2,5 anos, 456 dias, 91dias e 80\%, respectivamente, portanto, superiores em relação aos sistemas A, B e C. Estes valores são devidos ao uso de um plano forrageiro mais adequado à realidade da UPF, com maior nível de conhecimento e especialização do produtor, o que justifica o atual desempenho do rebanho. Entre as variáveis produtivas a DML e a produtividade por vaca, correspondem a 365 dias e 9 $\ell /$ vaca/dia, respectivamente.

Sistema de produção E - este sistema é constituído por unidades que desenvolvem a atividade leiteira combinada com bovinos de corte, dispõe em média: 2,5 UTH; 40ha de SAU, 
distribuídas em 1,5ha de feijão-preto (Phaseolus vulgaris), 0,5ha de sorgo (fabricação de vassoura), 1,5ha de mandioca, 3,5ha de milho, 1,5ha de canade-açúcar (fim forrageiro), 3ha de pastagens anuais de inverno (aveia/azevém) e 31,5ha de campo nativo; localiza-se em áreas com relevo íngreme, apresentando solos rasos (montanhoso) e pedregosos, e uma forte susceptibilidade à erosão; os equipamentos disponíveis são de uso manual e com TA.

A atividade leiteira apresenta uma baixa escala de produção de $16 \ell$ de leite/dia. As unidades possuem um rebanho com, aproximadamente, 18 vacas, 11 terneiros, 5 novilhas de ano e meio, 5 novilhas com mais de dois anos, 2 bois de serviço, 1 touro e 1 cavalo. As vacas são selecionadas quanto às características leiteiras entre o plantel de corte, onde predominam animais mestiços (Zebu/Holandês) provenientes da monta natural. Em relação à extração do leite, esta é totalmente manual.

Os valores médios para os indicadores reprodutivos IPP, IEP, PS e natalidade, são representados, respectivamente, por 3 anos, 600 dias, 274 dias e 60\%, refletindo as limitações gerências da unidade, o que conduz às baixas respostas das variáveis produtivas. A DMLR mostra que, embora haja uma prática de seleção dos animais com melhor aptidão leiteira e uma alimentação diferenciada para os mesmos, são poucos os que conseguem produzir no período de inverno. A produtividade de $2,52 \ell / \mathrm{vaca} / \mathrm{dia}$ é extremamente baixa ( $\ell / v a c a / d i a)$ como resultado de um ano de exploração da unidade.

Sistema de produção $\mathrm{F}$ - este sistema é composto por UPFs que praticam a combinação de atividades de produção de leite com bovinos de corte e agricultura de morro e dispõe em média: 3,5 UTH; 308 ha de SAU, distribuídas em 2ha de feijão, 7ha de vassoura, 5ha de mandioca, 15ha de milho, 5ha de cana-de-açúcar (fim forrageiro), 2ha de arroz, 6ha de pastagens anuais de inverno (aveia/azevém) e 272 ha de campo nativo; localiza-se em áreas que se assemelham ao sistema $\mathrm{E}$; os equipamentos disponíveis são de uso manual e de TA.

O leite é produzido numa escala diária de $42 \ell$ e tem, na disponibilidade do trabalho feminino, o fator fundamental para a manutenção da atividade. O rebanho é composto por 165 vacas, 111 terneiros, 53 novilhas de um ano e meio, 51 novilhas com mais de dois anos, 6 bois de serviços, 7 touros e 6 cavalos. As vacas que apresentam uma maior característica leiteira são selecionadas entre o plantel de corte e ordenhadas uma única vez no dia. Prevalecem no rebanho os animais mestiços
(Zebu/Charolês/Holandês) procedentes da monta natural. Realiza-se a exclusão de determinadas áreas de morro na primavera/verão com a finalidade de amenizar o desbalanço na alimentação do rebanho durante o outono/inverno. Os indicadores reprodutivos IPP, IEP, PS e natalidade apresentam valores de 3 anos, 500 dias, 260 dias e 70\%, respectivamente, resultado da baixa eficiência produtiva e reprodutiva do rebanho, mantendo as características de corte similares ao Sistema E, com objetivo de comercializar os terneiros.

Sistema de produção $G$ - este sistema é desenvolvido por unidades que praticam a combinação das atividades de produção de leite com bovinos de corte, e dispõe em média: 2,5 UTH; 80ha de SAU, distribuídas em 5ha de mandioca, 7ha de milho, 0,5ha de cana-de-açúcar (fim forrageiro), 10ha de pastagens anuais de inverno/verão (aveia/azevém e milheto) e 57,5ha de campo nativo; localiza-se geralmente em áreas de coxilha e tem origem com a divisão de antigas fazendas; os equipamentos disponíveis são de TM.

O leite é produzido numa escala de $36 \ell /$ dia, proveniente de um rebanho composto por 60 vacas, 41 terneiros, 19 novilhas com mais de ano e meio, 19 novilhas com mais de dois anos, 2 touros e 4 cavalos. As vacas leiteiras não ultrapassam 10 animais. $\mathrm{O}$ produtor procura manter as características raciais diferenciadas dos demais animais, inseminando ou cobrindo com touros que apresentem aptidão leiteira. Os valores médios dos indicadores reprodutivos IPP, IEP, PS e natalidade são representados por 3 anos, 511 dias, 156 dias e $71,43 \%$, respectivamente. Já as variáveis produtivas comportam-se com resultados superiores ao sistema E. Neste caso, os animais em produção apresentam um potencial superior para a característica leiteira, aproximadamente, $6 \ell /$ vaca/dia.

Sistema de produção $\mathrm{H}$ - este sistema é composto por unidades que desenvolvem a atividade leiteira como única fonte de renda, e dispõe em média 2,5 UTH; possui uma SAU média de 20ha, distribuídas em 2 ha de mandioca, 2ha de milho, 2ha de cana-de-açúcar (fim forrageiro), 3ha de pastagens anuais de inverno (aveia/azevém), 1ha de pastagem anual de verão (milheto) e 13ha de campo nativo; localiza-se em áreas que apresentam formações de encosta/coxilha; os equipamentos disponíveis são similares aos sistemas anteriores de uso manual e TA.

Prevalece no sistema uma escala de produção diferenciada, na qual a renda se encontra exclusivamente na atividade leiteira. $O$ volume comercializado é de, aproximadamente, $130 \ell$ de 
leite/dia. O rebanho é composto por 14 vacas, 10 terneiros, 5 novilhas de um ano e meio, 4 novilhas com mais dois anos, 2 bois de serviço e 1 eqüino. Predominam animais especializados na produção de leite (características raciais do Holandês), procedentes da inseminação artificial ou da monta natural com touros da mesma raça.

As variáveis reprodutivas IPP, IEP, PS e natalidade, representadas por 2,8 anos, 487 dias, 100 dias e $75 \%$, respectivamente, retratam que, embora, estes valores não sejam satisfatórios para a dinâmica do sistema, propicia uma evolução da UPF, repetindo as características limitantes observadas nos demais sistemas. O IEP, quando reduzido em três meses, desencadeia um efeito positivo nos indicadores reprodutivos. Com relação ao PS, este permite evidenciar a carência do controle leiteiro, uma vez que as unidades possuem alguns animais com baixo potencial.

Entre as variáveis produtivas DML e produtividade/vaca, aparecem os valores de 387 dias e $13,5 \ell / \mathrm{vaca} / \mathrm{dia}$, respectivamente. Esta situação apresenta algumas vantagens em relação aos sistemas anteriores, embora com limitações de manejo alimentar e reprodutivo. Ela leva o produtor, muitas vezes, a manter em lactação prolongada suas melhores vacas, evitando-se, assim, a redução da cota. A produtividade por animal mostra ser possível obter boas lactações com uma estrutura bastante simples, mas funcional mesmo sem a utilização de silagens, porém, com uma boa administração dos recursos forrageiros.

Sistema de produção I - neste sistema a atividade leiteira aparece como única fonte geradora de renda, similarmente ao sistema anterior, dispõe em média 2,5 UTH; 45ha de SAU, distribuídas em 1,0ha de mandioca, 8ha de milho, 0,5 ha de cana-deaçúcar (fim forrageiro), 6,0ha de pastagens anuais de inverno (aveia/azevém), 2ha de pastagem anual de verão (milheto) e 33,5ha de campo nativo; localizase em áreas que apresentam condições naturais similares ao sistema $\mathrm{H}$; as máquinas e equipamentos disponíveis são de uso manual, TA e TM, similares aos sistemas anteriores que desenvolvem agricultura na coxilha.

A atividade leiteira no sistema se distingue por uma escala comercializada de $120 \ell$ de leite/dia. O rebanho é constituído por 23 vacas, 18 terneiros, 9 novilhas de um ano e meio, 8 novilhas com mais de dois anos, 1 touro e 1 eqüino. Prevalecem, no rebanho, animais com características raciais do Holandês, procedentes da inseminação artificial ou da monta natural com o reprodutor da mesma raça. A carência alimentar acontece, freqüentemente, antes e após o período de utilização da silagem, entretanto as limitações na qualidade dos alimentos em termos de proteína costuma se manter durante o ano agrícola.

As variáveis reprodutivas IPP, IEP, PS e natalidade de 2,5 anos, 456 dias, 91 dias e 80\%, respectivamente, analisadas de forma isolada, tendem a apresentar melhores resultados quando comparadas com os demais sistemas. Porém, incluindo-se na análise as variáveis produtivas DML e produtividade/vaca, com valores de 365 dias e $7,7 \ell / \mathrm{vaca} / \mathrm{dia}$, respectivamente, evidenciam-se limitações relativas à interação entre índices reprodutivos e baixa produtividade/vaca. HILLESHEIM \& STUKER (1995) observaram, em situação similar, através de levantamento na região leste de Santa Catarina, uma produtividade média de 6,5 $\ell / \mathrm{vaca} / \mathrm{dia}$, com uma variação de 4 a $11 \ell /$ vaca/dia.

\section{CONCLUSÃO}

Os indicadores de desempenho zootécnico, observados entre as UPFs, evidenciam um potencial ainda não explorado pelos agricultores familiares associados da COOPROL, que é a associação de variáveis reprodutivas e a composição do rebanho combinadas à produtividade por animal que, quando trabalhadas em conjunto, podem otimizar o desempenho técnico, principalmente, dos sistemas A, B, E, F e G.

Os sistemas de produção C, D, H e I são modelos de produção de leite que tendem a apresentar características de estabilidade na produção durante o ano agrícola, fruto do tipo de gestão empregada ou da integração entre as atividades desenvolvidas nas UPFs.

A elaboração e execução de propostas de forrageamento para rebanhos nos sistemas, deve atender as demandas em quantidade e qualidade nas diferentes estações do ano agrícola, além de possuírem reservas para situações de frustração climática. Com a finalidade de evitar a instabilidade na renda das famílias, devem ser consideradas as limitações do terreno à motomecanização, a necessidade da renovação de equipamentos de tração animal, a ausência do controle leiteiro (que tem impossibilitado, na maioria das vezes, que os produtores apliquem programas de descarte em prol das melhores vacas) e a demanda no uso da mão-de-obra no decorrer do ano agrícola.

\section{REFERÊNCIAS BIBLIOGRÁFICAS}

ESCOSTEGUY, C, DAMBORIARENA, E, HETZEL, P., $\boldsymbol{e} \boldsymbol{t}$ al. A cadeia agroalimentar do leite: desafios aos pequenos produtores rurais. Ijui : Unijui, 1993. 43p. 
FAO/INCRA. Agricultura familiar na Região Sul. Brasília, 1996. 62p.

FARIAS, V.P., CORSI, M. Bovinocultura de leite fundamentos da exploração racional: índice de produtividade em gado de leite. Piracicaba : FEALQ, 1986. $580 \mathrm{p}$.

FARIAS, V.P., SILVA, S.C. O futuro dos sistemas de produção de leite no Brasil. In: SIMPÓSIO INTERNACIONAL, 1996, Juiz de Fora MG. Anais do simpósio internacional... Minas Gerais : EMBRAPA, CNPGL, 1996. p.77-89.
HILLESHEIM, A., STUKER, H. Duração da lactação, intervalo de partos e produção de leite no rebanho leiteiro do Leste de Santa Catarina. Revista Agropecuária Catarinense, Florianópolis, v.8, n.4, dez, p.19-23, 1995.

LIMA, A.P., BASSO, N., NEUMANN, P.S., $\boldsymbol{e t} \boldsymbol{a l}$. Administração da unidade familiar: modalidades de trabalho com agricultores. Ijui, RS : UNIJUI, 1995. $175 \mathrm{p}$.

LUCCI, C.S. Manejo de bovinos leiteiros. Bela Vista SP : MIR, 1997. 169p. 